Arteterapia. Papeles de arteterapia y educación para inclusión social ISSN-e 1988-8309

http://dx.doi.org/10.5209/ARTE.57581

\title{
III Congreso Nacional de Arteterapia (FEAPA)
}

Cristina Ramos Ruiz ${ }^{1}$

El III Congreso Nacional de Arteterapia (FEAPA) y terapias artísticas, tuvo lugar los días 19,20 y 21 de mayo de 2017, en el campus de la Merced de la Universidad de Murcia. Se celebró con el objetivo de "articularse como punto de encuentro, intercambio y reflexión crítica entre profesionales, así como de difundir lo que propone y aporta la Arteterapia en sus distintos campos de aplicación". El congreso organizó conferencias plenarias, mesas de comunicaciones, talleres de Terapias Creativas y la exposición de pósteres junto a la I Convocatoria internacional de Investigación en Arteterapia, la I Bienal de Arte Contemporáneo en Arte Outsider "creatividad y pulsión" y la Convocatoria de Arte Comunitario y Participativo, en colaboración con el Centro de Estudios de Terapias Creativas (CETEC) y la Universidad de Murcia, permitiendo a los asistentes y a la comunidad, "crear dinámicas de participación colectiva”.

La coordinación de diversas comisiones, por parte de Francisco Coll Espinosa: científica, organizativa, divulgativa, investigadora y del comisariado de arte participativo; posibilitó, junto a la secretaría por parte de Teresa Moreno, Marina Martínez y Ana Martín, y todos los miembros de la junta directiva de FEAPA, el desarrollo de un congreso colmado de acontecimientos novedosos.

El congreso se inició con la mesa inaugural "Fundamentos de las terapias creativas: Proceso creativo y proceso de creación" de la mano de Francisco Coll Espinosa y Javier Corbalán Berná, en representación del CETEC, junto a Miquel Izuel Curriá a cargo de la presidencia de FEAPA, quien afirmó que "el camino al reconocimiento profesional pasa por demostrar los beneficios de la Arteterapia”. Las ponencias destacaron por la riqueza de su contenido y la mirada acto creador, también contamos con algunas presentaciones de proyectos que se están desarrollando en el momento y suponen un hito en la historia de la Arteterapia en España y Europa.

Eva Mesas Escobar Y Juan Gracia SandovaI presentaron la I Bienal contemporánea en arte outsider con el título "Creatividad y pulsión”, así como a los artistas y las obras que participaban en la propuesta. Ángel Cagigas Balcaza con: Construyendo presencias, notas sobre el Arte Outsider, Lola López Mondéjar y su reflexión sobre la autorreparación a través del arte citando a autores como Ferenczi, André Green, Fiorini o Alice Munroe. Marian López F-Cao, presentó Aletheia, un proyecto para integrar el dolor, en torno al primer I+D de Arteterapia, otorgado en España, para investigar acerca de trauma, arteterapia y memoria emocional. Tras una descripción de

Educadora social, psicopedagoga y arteterapeuta. Presidenta de AFIA. Directora de la Unidad de Arteterapia y psicopedagogía en el Instituto Centta

E-mail cristina.ramos@centta.es 
la alexitimia como consecuencia del trauma, se presentó la arteterapia como una herramienta apropiada para recuperar la expresión emocional. Miquel Izuel, analizó en su ponencia, las particularidades de la Arteterapia frente a otras disciplinas. Mónica Sorín, nos colmó de buen hacer reflexionando sobre El cuerpo en el trabajo arteterapéutico, el cuerpalma, como ella lo denomina, cargado de huellas de historia citando a Foucault. Sybille Csery abordó el estado del proyecto NEAT, Red Europea de Asociaciones de Arteterapia, un plan de coordinación entre las asociaciones con el fin de desarrollar la identidad profesional da la Arteterapia en Europa, intercambiar intereses entre ambas, crear una base de datos sobre investigaciones y publicaciones en Arteterapia, apoyar la investigación, definir estándares mínimos para el ejercicio de la Arteterapia entre otros deseos. Consideramos que esta iniciativa es de gran valor y supone un paso adelante significativo para el mejora de nuestra profesión.

Las mesas de comunicaciones de gran variedad, formaron un congreso representativo de los múltiples ámbitos en los que se desarrolla la Arteterapia: social, en museos o espacio públicos, comunitario, en asociaciones o residencias de ancianos; educativo, educación primaria o extraescolar, en el ámbito clínico: hospitales psiquiátricos, centros de salud, clínicas de especialidades o en consulta privada, del ámbito universitario, investigaciones doctorales y atención temprana, entre otros. Contamos con la participación de Laura López, Rosa $\mathrm{M}^{\mathrm{a}}$ Rodríguez, Iratxe Caño Esteban, Kathya Adsuar, Francisco Coll, María del Rocío Sánchez, Miriam Alcolea, con proyectos muy variados desde Arteterapia en un hospital de día con adultos a intervención en atención temprana con niños pre-psicóticos o con pacientes amputados en un hospital, todos ellos con resultados muy favorables. Experiencias de arteterapia en salud mental con adultos, Sofía Martín Mellado, Cristina Ramos Ruíz, y Carmen Delgado (relatora) narraron intervenciones pertenecientes al ámbito clínico. Comunicaciones desde en el ámbito social y asistencial. Lucía Hervás, Liliana Montoya, María Teresa Moreno, Francisco Coll, Patricia Mañas y Lola Fernández, Ana Hernández, María Montero, Clara Centenera Ribas y Ana Álvarez Giménez. Experiencias de arteterapia en diversidad funcional y comunidad: Tania Ugena, Raquel Tijano, Catalina Guerrero, Loli Miguel, Beatriz Sorín y Andrea López, $\mathrm{M}^{\mathrm{a}} \mathrm{Sol}$ Revert, Elena González, Cristina Ramos y Ana Serrano, Andrea López Iglesias, Jesús Gracia y Rosa Barquero, Carolina Peral, Pilar Ascaso y Mar Cobos que se centraron en la investigación en trauma, la intervención en psicosis y en hospitalización infantil respectivamente.

La variedad de las temáticas y propuestas favoreció un seguimiento activo de la audiencia que ejerció el apoyo con sus preguntas y reflexiones. Resulta esperanzador para la profesión observar la multitud de proyectos que se vienen realizando y la calidad de los mismos. El rigor con el que se aplican y la presencia de una estructura común, una base que unifica y consolida la disciplina como una fuente inagotable de herramientas y recursos de gran valor para la intervención terapéutica.

Simultáneamente, se realizaron talleres de terapias artísticas. Psicodrama de la mano de Cristina Massini y Danza Movimiento Terapia (DMT) por Carolina Jiménez; Meditándome, de Cristina Geremias Llinàs, y El títere de sombras como herramienta de trabajo en Arteterapia, guiado por Eva Mesas Escobar., Bio-grafías y Sueño social y creación comunitaria, fueron dinamizados por Sofía Martín Mellado y Paz Martinez Loné y Liliana Montoya Delacruz respectivamente. Hubo gran afluencia y muy buenas críticas por parte de sus asistentes quienes valoraron la diversidad de oferta y que apreciaron la posibilidad de cambiar de escenario para 
adquirir un aprendizaje más práctico. Este tipo de espacios son de especial riqueza ya que permiten el intercambio personal y la adquisición de recursos para la práctica profesional, favorecen un aprendizaje integral, del cuerpo y la mente, y una experiencia de encuentro y crecimiento personal.

Se realizaron las presentaciones de tres libros de interés para la profesión: Actividades Artísticas y creativas en terapia ocupacional de Ana Hernández Merino y María Montero- Ríos Gil, Una espina en la carne de Lola Lopez Mondejar y Reflexiones sobre la supervisión en Arteterapia por Francisco Coll Espinosa.

El encuentro terminó con la entrega de premios de arte participativo y arte outsider y se prorrogó la fecha de entrega de trabajos para la Convocatoria Internacional de Investigación en Arteterapia. Una animada y musical despedida nos permitió improvisar la expresión de nuestra vivencia y cerrar así un congreso muy enriquecedor y motivador.

Agradecemos a toda la organización, la inmensa labor de poner en común tanto talento y buen hacer. Observamos la importancia de la presencia de distintos profesionales de las terapias artísticas quienes nos aportan enorme riqueza con las distintas herramientas y recursos que manejan. Consideramos un importante avance esta apertura hacia la inclusión de distintos lenguajes artísticos desde el que ser creadores. Creadores de relatos, imágenes, danzas; obras que nos ponen en común con el otro y permiten el encuentro y la expresión de sí en un lugar y un momento, en un encuadre arteterapéutico. Por ello creemos que la presencia de distintos talleres ha supuesto una opción excepcional y animamos a los lectores a compartir su experiencia en forma de talleres en los congresos venideros.

Queremos agradecer especialmente la labor de coordinación entre la Junta FEAPA y las distintas asociaciones, a nuestras representantes, Mónica Cury Abril y Ana Serrano Navarro, quienes favorecieron la participación de tantas socias de Afia como ponentes o talleristas, gracias a la difusión de la información decretada en numerosas reuniones y encuentros organizativos.

Valoramos profundamente el encuentro personal entre profesionales, estudiantes y las distintas asociaciones ya que esto permite que el futuro de la Arteterapia este respaldado por la unidad de todos nosotros lo cual supondrá el mayor garante de profesionalidad y sentimiento de disciplina. Seguiremos trabajando para visibilizar la Arteterapia y fortalecer el lugar que ocupa en la sociedad, así como tejiendo redes que permitan sentar las bases de un futuro profesional bien definido y consolidado. 